\title{
Analysis of Online Teaching Mode and Effect of Computer Network under Large-Scale Users
}

\author{
https://doi.org/10.3991/ijet.v15i20.17423 \\ Jiyu Zheng \\ Henan University of Engineering, Zhengzhou, China \\ zhengji yu@haue.edu.cn
}

\begin{abstract}
Under the influence of the epidemic situation, many teachers and students choose the online teaching of computer network. We should study how to use the online teaching of computer network on a large scale. Based on the online teaching data of the school, this paper makes a comparative analysis of the functions and teaching methods of the computer network teaching platform. Through the feedback survey of teachers and students, most of them are satisfied with the online teaching of computer network, but there are also some problems. These problems are: teachers and students do not adapt to the new online teaching method; they are not familiar with the software of network platform, which makes it difficult to use; there are technologies in the teaching process, such as not fluent, unable to log in, unable to open web pages, etc Question. Through the continuous improvement of computer network teaching problems, teachers and students experience better and better, and their satisfaction is higher and higher. Generally speaking, online teaching of computer network has become an important teaching method, which will continue to be valued and applied in the post epidemic era.
\end{abstract}

Keywords-Computer network, online education, teaching method, effect.

\section{Introduction}

Under the novel coronavirus epidemic situation there was no parallel in history. The traditional contact teaching method was unable to carry out the teaching. Instead, it was taught online by computer network. But this kind of large-scale online teaching method has never been used before. What method, how to carry out the teaching, how to achieve the effect, and what problems exist should be studied in practice.

Computer network teaching is changing our teaching methods and processes and has a huge impact on teaching methods [1-3]. In the early stage of computer network teaching, it only serves as an auxiliary role, but with the development of online teaching, it has gradually become the mainstream form, especially when the traditional teaching method cannot be adopted [4-6]. Wilson and Stacey [7] thinks that the interaction between teachers and students in the process of online teaching is very important to the teaching effect, introduces the teaching methods of information and communication technology, and puts forward suggestions for the development of 
online teaching personnel. Teachers play an important role in the teaching process and learning methods. With the popularization of computers, the traditional classroom teaching has been impacted, and the hybrid teaching method combined with online teaching has been paid more and more attention [8]. Comas-Quinn [9] collected relevant data through investigation, studied the mixed teaching challenges faced by teachers, evaluated the impact of introducing mixed learning into distance language learning courses on teachers, and believed that the change of teachers was generated in the process of traditional classroom teaching to network teaching, which not only acquired information and communication technology skills, but also required new media teaching To understand and accept the new role of online teacher. Clark-Ibanez [10] discusses the advantages and challenges of computer network teaching and puts forward some curriculum experience. These useful suggestions include student preparation, discussion for learning, interactive communication, integration of multimedia and assessment courses.

During the teaching process of online courses, students can anonymously express their personal opinions, so that teachers can modify the teaching scheme according to their opinions and suggestions, and constantly promote the improvement of online teaching quality $[11,12]$. The computer network course is more and more popular in higher education, which is very helpful for teachers to improve their teaching skills [13-15]. With the development of network technology and the continuous improvement of network transmission speed, people are more and more interested in online education. It improves the participation and interaction of students. This novel teaching method is also popular among young students [16-18]. Marek [19] conducted an online survey of master's courses in a certain region, got feedback from students, selected useful parts for teachers, and put forward the organization support mode of online courses, which helps to improve the understanding of online teaching. Brooke [20] adopts case teaching as a method of network teaching. Through case teaching, students can be promoted and encouraged, and finally students can be inspired to divergent thinking and have their own ideas and plans. Tsai et al. [21] in order to study how teachers can participate in and benefit from computer network teaching, a sample survey was conducted to analyze the perception of participation in network learning process on growth. Students have a high evaluation of the practicability and simplicity of online learning, and generally believe that online teaching is effective. Garrison et al. [22] takes the computer network as the medium and can carry out education through the network meeting. He proposes that the three elements of cognitive existence, social existence and teaching existence constitute the education model. The research holds that the computer network meeting has considerable potential in education. Berge [23] pointed out the key points of online teaching. The preparation of online teaching is as important as the online teaching process, and the communication with students is strengthened. Some scholars analyzed the impact of epidemic situation on teaching, future teaching prospects and how to carry out online teaching under the situation of epidemic situation [24-26], in the meantime, some of them deeply analyzed the theory, environment, methods and tools of online teaching under the new situation [27-29]. 
This paper studies the online teaching method and teaching effect of computer network, including the introduction, the basic situation of computer network teaching in a university, the platform and teaching method of network teaching, the effect of computer network teaching, the improvement of online teaching problems, and finally gives the conclusion.

\section{Basic Information of Computer Network Teaching}

Due to the impact of the epidemic situation, the school adopts computer network teaching. Therefore, the school has carried out many times of network teaching software training in order to achieve good online teaching effect. In this semester, there are 966 teachers and 20938 students participating in the online teaching of theoretical courses in Henan University of engineering. In the third week (March 2-5, 2020), 709 theoretical courses should be opened, 688 online courses should be opened, and the normal opening rate is $97 \%$. The reason why the class didn't start normally was that some teachers didn't have the online class conditions.

According to statistics (see Table 1), there are 881 teachers in the third week of this semester, 876 normal online teachers and 5 non normal online teachers. The proportion of normal online teachers is $99.43 \%$. The reasons why five people didn't teach online are: Spring Festival holiday to the countryside for the new year, they haven't returned to school, teachers to the countryside for the new year don't carry laptops, and they lack hardware. In addition, there is no network in some rural areas, or there is no network installed at home.

There are 28604 students in the whole school. There are 20938 students with teaching arrangement in this semester, 20735 students with online learning conditions and 203 students without online learning conditions. $99.03 \%$ of the students are qualified to participate in online learning. The reasons why students teach online classes are similar to those of teachers. First, there is no computer, second, the network signal is not smooth, or there is no network in some mountainous areas. Second, they are not familiar with the teaching software. In addition, the online platform is blocked and unable to use.

Table 1. Basic information of computer network teaching

\begin{tabular}{|l|c|c|c|c|c|c|}
\hline \multicolumn{1}{|c|}{ Online teaching } & Course & Ratio & Teacher & Ratio & Student & Ratio \\
\hline Online & 688 & $97 \%$ & 876 & $99.43 \%$ & 20735 & $99.03 \%$ \\
\hline Not online & 21 & $3 \%$ & 5 & $0.57 \%$ & 203 & $0.97 \%$ \\
\hline
\end{tabular}

\section{Network Teaching Platform and Teaching Methods}

According to statistics of Henan University of engineering, 2872 courses including public courses and professional courses are offered in the third week of this semester, with 5744 class hours and 191351 online students. Teachers use various teaching platforms to organize online teaching by recording, broadcasting, synchronous class- 
room and hybrid teaching methods, and by establishing QQ, wechat and Dingding groups with students.

At present, most of the computer network teaching platforms used by teachers mainly include MOOC, Dingding, Tencent classroom / conference, Chaoxing, yuketang, lanmo, etc., all of which have live broadcast function except MOOC. MOOC mainly provides remote education by recording and broadcasting. This way aims at some main courses, which have curriculum resources on the platform. Students watch other teachers' recording and broadcasting Video, meet problems and then communicate with teachers. This method is very suitable in the case of streaming. For online live teaching platforms, most of them have functions such as live broadcast, check-in, course sharing, video broadcast, communication and interaction, homework, data export, etc., with slightly different specific functions. The function comparison of online teaching platform is shown in Table 2.

Table 2. Function comparison of online teaching platform

\begin{tabular}{|l|l|c|c|c|c|c|}
\hline Teaching stage & \multicolumn{1}{|c|}{ Function } & Dingding & Tencent class & Chaoxing & Yuketang & MOOC \\
\hline \multirow{4}{*}{$\begin{array}{l}\text { Teaching man- } \\
\text { agement }\end{array}$} & Sign in & Yes & Yes & Yes & Yes & Yes \\
\cline { 2 - 7 } & Course encryption & No & No & No & No & Yes \\
\cline { 2 - 7 } & Course playback & Yes & Yes & Yes & Yes & Yes \\
\cline { 2 - 7 } & Course sharing & Yes & Yes & Yes & Yes & No \\
\cline { 2 - 7 } & Family school group & Yes & No & Yes & No & No \\
\hline \multirow{4}{*}{$\begin{array}{l}\text { Teaching pro- } \\
\text { cess }\end{array}$} & Screen sharing & Yes & Yes & No & No & No \\
\cline { 2 - 7 } & Courseware play & No & Yes & Yes & Yes & Yes \\
\cline { 2 - 7 } & Play video & Yes & Yes & Yes & Yes & No \\
\cline { 2 - 7 } & $\begin{array}{l}\text { Teachers' appear- } \\
\text { ance }\end{array}$ & Yes & Yes & Yes & Yes & No \\
\cline { 2 - 7 } & Communication & Yes & Yes & Yes & Yes & Yes \\
\hline \multirow{2}{*}{$\begin{array}{l}\text { Teaching evalu- } \\
\text { ation }\end{array}$} & Instant test & No & Yes & Yes & Yes & No \\
\cline { 2 - 7 } & Homework & Yes & Yes & Yes & Yes & Yes \\
\cline { 2 - 7 } & Data export & Yes & Yes & Yes & Yes & No \\
\hline
\end{tabular}

The teaching platform used by the teachers is shown in Figure 1. The most used platform is Chaoxing. The reason is that the school has close cooperation with Chaoxing. Chaoxing has given serious training to the teachers. Most of the teachers are familiar with the platform, but the platform is not smooth at the initial stage of operation, or even the network is paralyzed during the live broadcast. In these platforms, Dingding and Tencent classes are the ones with good network evaluation, with smooth live broadcast and good effect. In the case of Dingding used by many teachers in the whole country, there was only one network crash, and the platform was repaired in time. The author of this paper has been using Tencent classroom, there is no case of network connection is not smooth. Some teachers use the existing teaching resources of MOOC platform to let students directly watch the teaching video and only conduct online tutoring, which also achieves good results.

Each teaching platform has many functions, which can be broadcast live, recorded or mixed. As shown in Figure 2, most of the teachers adopt hybrid teaching method, accounting for $83 \%$, and their colleagues adopt live broadcast, video broadcast, course 
sharing, discussion, etc.; $11 \%$ of the teachers adopt video playback, which is mainly due to the instability of various platforms in the early stage. Live broadcast accounts for $6 \%$. With the continuous stability of the platform, more and more teachers choose live broadcast.

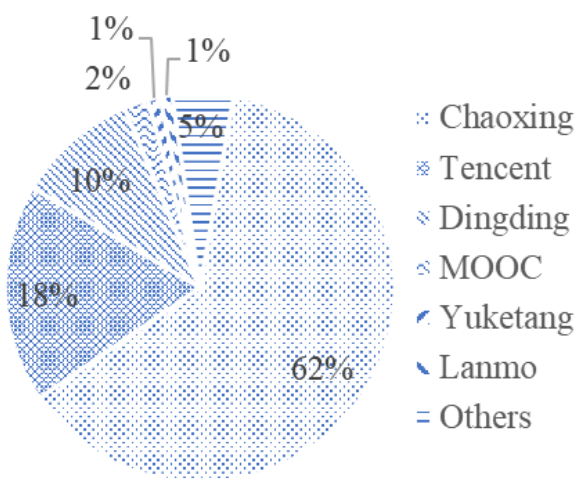

Fig. 1. Computer network teaching platform selected by teachers

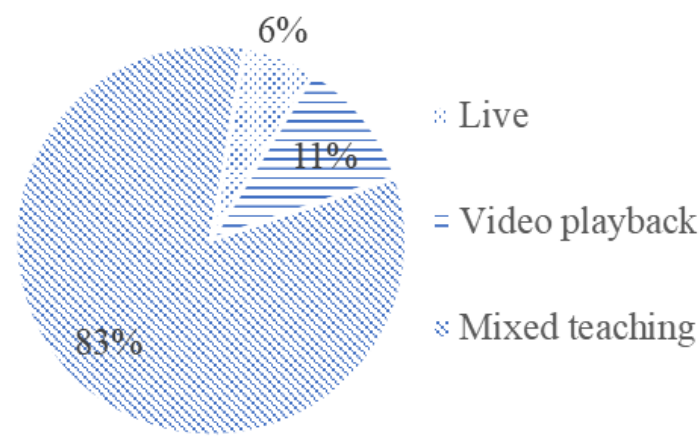

Fig. 2. Teaching methods of Teachers

\section{$4 \quad$ Teaching Effect of Computer Network}

\subsection{Teacher's feedback}

The change of teaching method is a change, which can be accepted by young teachers quickly. But for older teachers, habits are difficult to change. How about the effect of large-scale online computer network teaching? There has never been such a survey before. Through the online questionnaire survey of 387 teachers and 2733 courses, the evaluation results show that the teachers are basically satisfied with the online teaching form, as shown in Figure 3, the online teaching effect can meet the students' learning requirements. 
Through the function comparison of the online teaching platform in front, all online teaching platforms can have interactive communication. Through this function, teaching can ask students whether they understand, and students can reflect problems to teachers for timely communication. To improve the teaching effect. According to the survey and statistics of communication and interaction, the proportion of very good and good is $26 \%$ and $55 \%$ respectively, and the sum of the two is $81 \%$. Therefore, the effect of online communication and interaction is generally good, and the evaluation of the effect of online communication and interaction is shown in Figure 4.

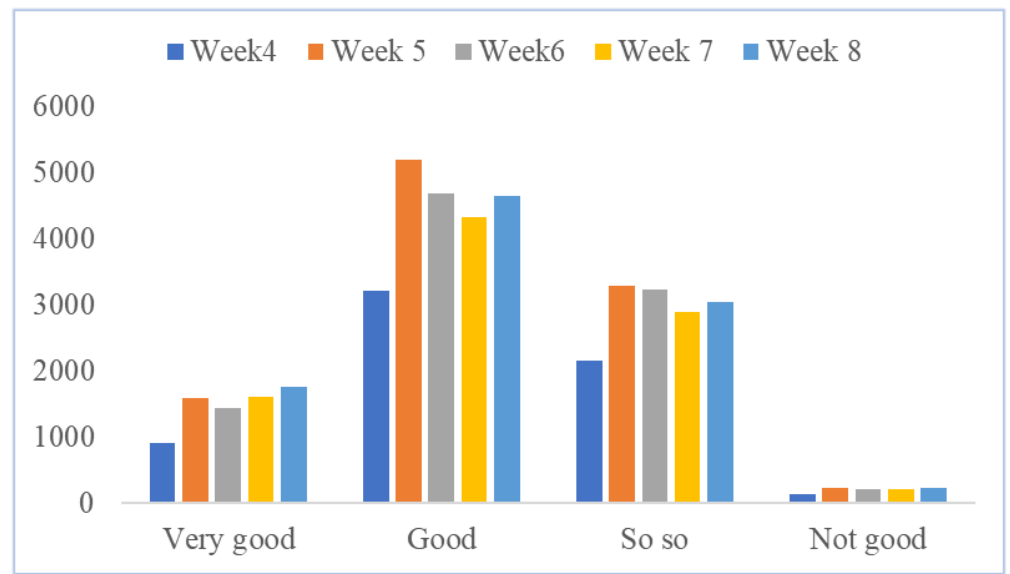

Fig. 3. Evaluation of teaching effect

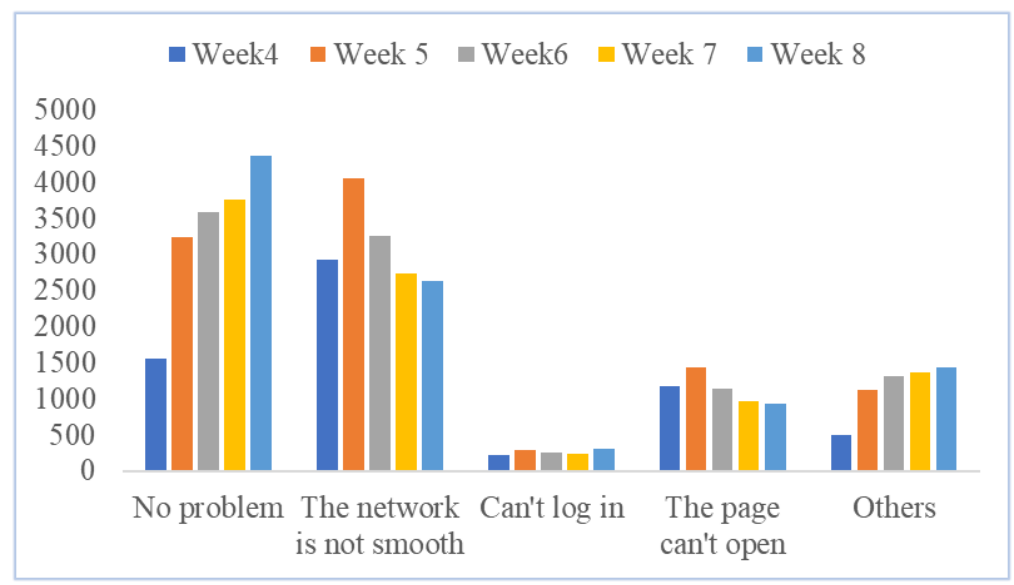

Fig. 4. Teachers' Evaluation on the effect of communication and interaction

In the process of teachers' online teaching, most of the teachers do not encounter technical problems, but some of them have technical problems that affect the teaching process. These problems mainly include the network is not smooth, the web page cannot be opened, cannot log in and so on, as shown in the figure. The root of the 
above technical problems lies in the small capacity of the software platform. When a large number of people log on to the online teaching platform, the network is not smooth. In serious cases, the web page cannot be opened or logged on. The technical problems affecting the teaching are shown in Figure 5.

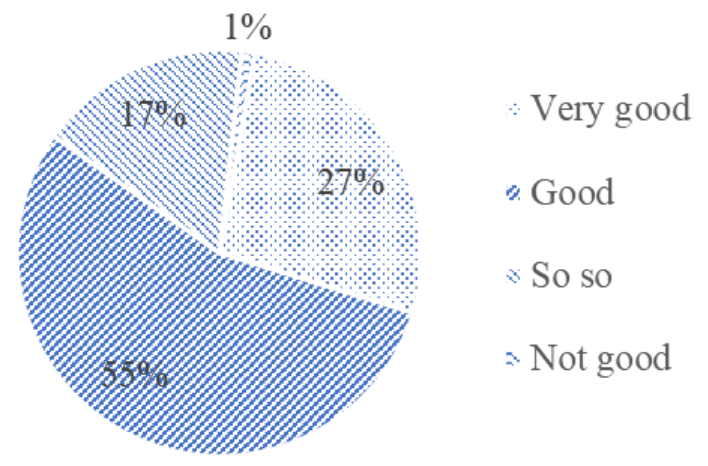

Fig. 5. Technical problems of computer network online teaching

\subsection{Student feedback}

According to the survey of 6993 students, students basically agree with the form of online teaching. As shown in Figure 6, the number of students supporting the network platform for the current courses is Chaoxing, Tencent (including Tencent classroom, Tencent conference, WeChat, QQ) and Dingding are also used more, while the number of other platforms is less. In the previous analysis, $62 \%$ of teachers use Chaoxing, but less than $50 \%$ of students support it, indicating that some students do not approve of the platform. Although Tencent and Dingding use $28 \%$ of teachers, the proportion of students' support is close to $50 \%$.

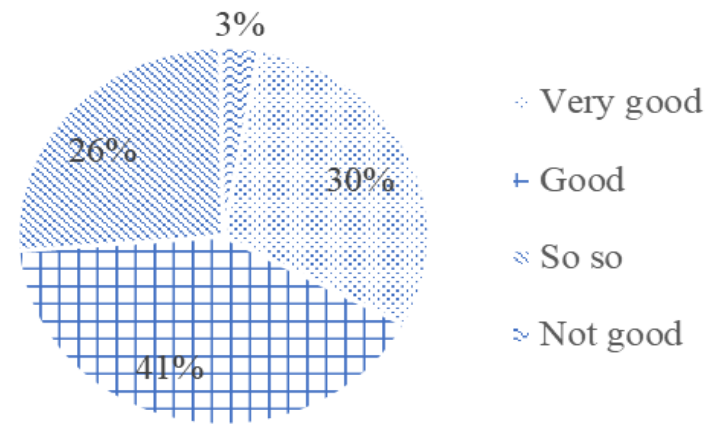

Fig. 6. Number of students' support for network platform 
Students' satisfaction with online teaching as shown in Figure 7, very good and good accounting for $27 \%$ and $55 \%$ respectively. The sum of the two accounts for $82 \%$ and the general and dissatisfied accounts for $18 \%$, which is basically consistent with the satisfaction of teachers' online teaching effect. The reasons why students are not satisfied with the teaching effect are comprehensive, including the reasons of network technology, teachers, and online teaching mode itself. We need to improve and get used to it.

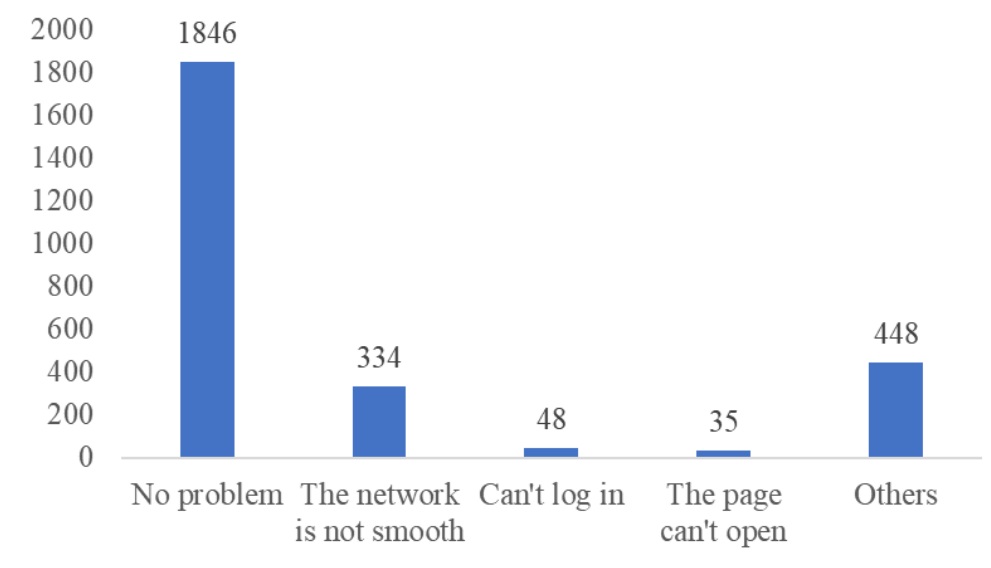

Fig. 7. Students' evaluation of teaching effect

As shown in Figure 8, the satisfaction of online communication, very good and good accounting for $30 \%$ and $41 \%$ respectively, and the sum of the two is $71 \%$, which is relatively satisfactory in general. However, compared with teachers' satisfaction with the effect of communication and interaction, it shows that not all students have the opportunity of communication and interaction in the teaching process. Some students who have never had communication and interaction think that the effect of interaction and communication is general or not good.

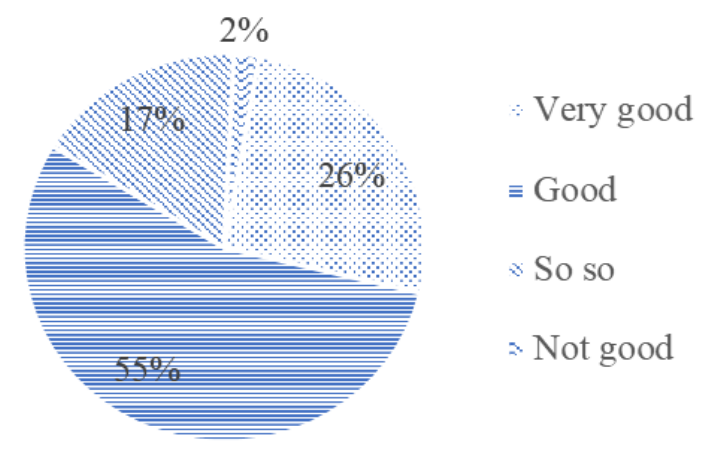

Fig. 8. Students' satisfaction with communication and interaction effect 


\section{The Improvement of Computer Network Teaching}

\subsection{Solutions to the problems of teaching technology}

During the epidemic period, various schools chose computer network teaching. In the early stage of computer network teaching, there were various technical problems, such as the network was not smooth, the network collapsed, unable to log on and so on. In the face of the first large-scale online teaching in human history, the capacity of various platforms is insufficient at the initial stage, and there is no experience to learn from. Only when there is a problem, it can solve the problem in time, expand the capacity, and improve the level of network platform, such as Dingding emergency increase the server, improve the online capacity, and then there is no collapse. With the development of the follow-up teaching, there are fewer and fewer problems, and the network platform is more and more fluent. Some small platforms are abandoned by users, and large and more fluent network platforms are selected for teaching. The comparison of network teaching technical problems is shown in the figure. The situation of non-fluency is improving, and the number of users who do not encounter technical problems is increasing, as shown in Figure 9.

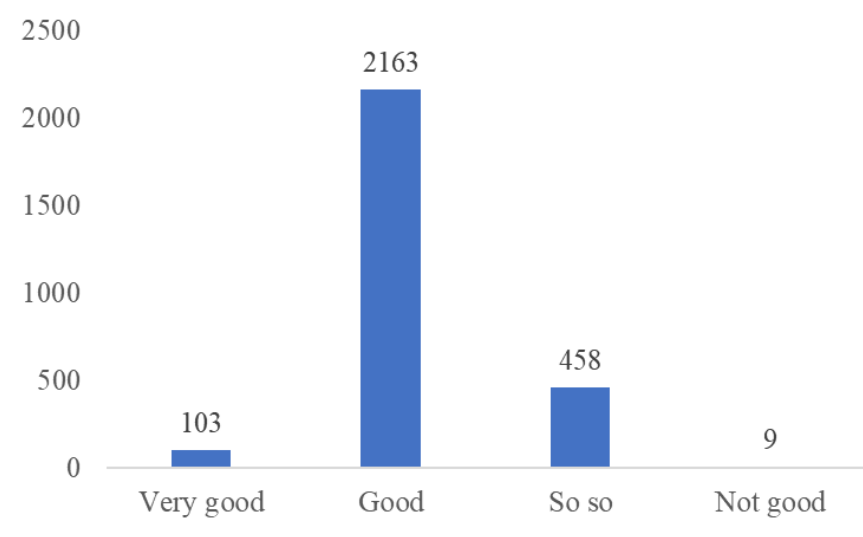

Fig. 9. Improvement of online teaching technology

Students are becoming more and more satisfied with their individual learning effects (as shown in Figure 10). Less and less technical problems affecting online teaching have great help to students' learning experience. Secondly, students are more and more adapt to online teaching. The improvement of students' satisfaction with online teaching is a gradual process, and the same new teaching method needs to be recognized gradually. Students' recognition of online teaching will be higher and higher. 


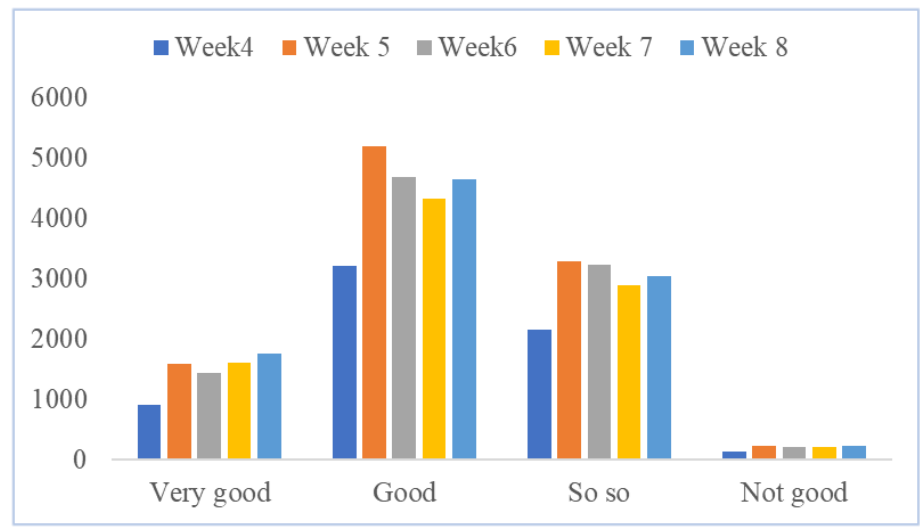

Fig. 10. Improvement of students' learning effect

\section{Conclusion}

This paper introduces the current network teaching platform used by the school and makes a comparative analysis of the functions of the network teaching platform. The functions of these teaching platforms basically meet the needs of daily teaching and provide a good experience for teachers. From the perspective of teaching effect, Tencent and Dingding platform have high teaching satisfaction, smooth network and complete functions. The teaching methods are mainly mixed, including online live broadcast, recording broadcast, communication with communication software and other auxiliary ways.

From the feedback of teachers and students, the online teaching effect, communication and interaction effect and teaching platform effect are all better, and the satisfaction of teachers is higher than that of students. An important reason for dissatisfaction may be technical problems, such as the network is not smooth, unable to log in, unable to open the network.

The main problems in the teaching of computer network are technical problems. With the development of teaching, the effect of using the software is getting better and better. In addition, teachers and students should adapt to the change of teaching methods, get used to this teaching method, and be familiar with the software platform, so as to make the classroom effect better.

\section{$7 \quad$ Acknowledgement}

The authors gratefully acknowledge the support of Doctoral Fund Project of Henan University of Engineering (2016025). 


\section{$8 \quad$ References}

[1] Yang, J., Lee, T. Y., Chen, B., Zhang, W. (2019). A comprehensive teaching reform model for a computer networks course based on integrated information systems, International Journal of Emerging Technologies in Learning, 14(18), 76-91. https://doi.org/10.3991/ijet. v14i18.11040

[2] Tsai, I. C. (2012). Understanding social nature of an online community of practice for learning to teach. Journal of Educational Technology \& Society, 15(2), 271-285.

[3] Patmanthara, S., Yuliana, O. D., Dwiyanto, F. A., Wibawa, A. P. (2019). The use of ladder snake games to improve learning outcomes in computer networking, International Journal of Emerging Technologies in Learning, 14(21), 243-249. https://doi.org/10.3991/ijet.v14i 21.10953

[4] Laciok, V., Bernatik, A., Lesnak, M. (2020). Experimental implementation of new technology into the area of teaching occupational safety for industry 4.0. International Journal of Safety and Security Engineering, 10(3), 403-407. https://doi.org/10.18280/ijsse. $\underline{100313}$

[5] Johnson, R., Stewart, C., Bachman, C. (2015). What drives students to complete online courses? What drives faculty to teach online? Validating a measure of motivation orientation in university students and faculty. Interactive Learning Environments, 23(4), 528-543. https://doi.org/10.1080/10494820.2013.788037

[6] Pei, J.Y., Shan, P. (2019). A micro-expression recognition algorithm for students in classroom learning based on convolutional neural network. Traitement du Signal, 36(6), 557-563. https://doi.org/10.18280/ts.360611

[7] Wilson, G., Stacey, E. (2004). Online interaction impacts on learning: Teaching the teachers to teach online. Australasian journal of educational technology, 20(1), 33-48. https://doi.org/10.14742/ajet.1366

[8] Martin, F. G. (2012). Will massive open online courses change how we teach? Communications of the ACM, 55(8), 26-28. https://doi.org/10.1145/2240236.2240246

[9] Comas-Quinn, A. (2011). Learning to teach online or learning to become an online teacher: An exploration of teachers' experiences in a blended learning course. ReCALL, 23(03), 218-232. https://doi.org/10.1017/S0958344011000152

[10] Clark-Ibanez, M., Scott, L. (2008). Learning to teach online. Teaching Sociology, 36(1), 34-41. https://doi.org/10.1177\%2F0092055X0803600105

[11] Hoehn Anderson, K., Friedemann, M. L. (2010). Strategies to teach family assessment and intervention through an online international curriculum. Journal of Family Nursing, 16(2), 213-233. https://doi.org/10.1177\%2F1074840710367639

[12] Hummer, D., Sims, B., Wooditch, A., Salley, K. S. (2010). Considerations for faculty preparing to develop and teach online criminal justice courses at traditional institutions of higher learning. Journal of Criminal Justice Education, 21(3), 285-310. https://doi.org/10. 1080/10511253.2010.488108

[13] Bullock, S. M. (2011). Teaching 2.0:(re) learning to teach online. Interactive Technology and Smart Education, 8(2), 94-105. https://doi.org/10.1108/17415651111141812

[14] Meseguer-Martinez, A., Ros-Galvez, A., Rosa-Garcia, A. (2017). Satisfaction with online teaching videos: A quantitative approach. Innovations in Education and Teaching International, 54(1), 62-67. https://doi.org/10.1080/14703297.2016.1143859

[15] King, K. M. (1994). Leading classroom discussions: Using computers for a new approach. Teaching Sociology, 22(2), 174-182. https://doi.org/10.2307/1318563

[16] Johnson, D. (1995). Student access to Internet: Librarians and teachers working together to teach higher level survival skills. Emergency Librarian, 22(3), 8-12.

[17] Ganesh, L. (2013, December). The effect of comic strips as a supplementary material to teach computer networks. In 2013 IEEE Fifth International Conference on Technology for Education (t4e 2013), Kharagpur, India, 184-191. https://doi.org/10.1109/T4E.2013.63 
[18] Jamie, D. M. (2002). Using computer simulation methods to teach statistics: A review of the literature. Journal of Statistics Education, 10(1), 63-70. https://doi.org/10.1080/106918 $\underline{98.2002 .11910548}$

[19] Marek, K. (2009). Learning to teach online: Creating a culture of support for faculty. Journal of Education for Library and Information Science, 50(4), 275-292.

[20] Brooke, S. L. (2006). Using the case method to teach online classes: Promoting socratic dialogue and critical thinking skills. International Journal of Teaching and Learning in Higher Education, 18(2), 142-149.

[21] Tsai, I. C., Laffey, J. M., Hanuscin, D. (2010). Effectiveness of an online community of practice for learning to teach elementary science. Journal of Educational Computing Research, 43(2), 225-258. https://doi.org/10.2190\%2FEC.43.2.e

[22] Garrison, D. R., Anderson, T., Archer, W. (1999). Critical inquiry in a text-based environment: Computer conferencing in higher education. The internet and higher education, 2(2-3), 87-105. https://doi.org/10.1016/S1096-7516(00)00016-6

[23] Berge, Z.L. (2013). E-Moderating: the key to teaching and learning online. Distance Education, 34(3), 391-395. https://doi.org/10.1080/01587919.2013.835769

[24] Poth, R.D. (2020). Embracing the unexpected: K-12 education and online teaching in the time of coronavirus. Journal of Digital Learning in Teacher Education, 36(3), 151-163. https://doi.org/10.1080/21532974.2020.1774039

[25] Raymond-Hayling, O. (2020). What lies in the year ahead for medical education? A medical student's perspective during the COVID-19 pandemic. Medical Education Online, 25(1), 1781749-1781749. https://doi.org/10.1080/10872981.2020.1781749

[26] Sandhu, P., de Wolf, M. (2020). The impact of COVID-19 on the undergraduate medical curriculum. Medical Education Online, 25(1), 1764740. https://doi.org/10.1080/10872981. 2020.1764740

[27] Sellnow-Richmond, D., Strawser, M. G., Sellnow, D. D. (2019). Student perceptions of teaching effectiveness and learning achievement: A comparative examination of online and hybrid course delivery format. Communication Teacher, 34(3), 112-131. https://doi.org/10. $1080 / 17404622.2019 .1673456$

[28] Abi-Rafeh, J., Azzi, A. J. (2020). Emerging role of online virtual teaching resources for medical student education in plastic surgery: COVID-19 pandemic and beyond. Journal of Plastic, Reconstructive \& Aesthetic Surgery, 148-160. https://doi.org/10.1016/j.bjps.2020. $\underline{05.085}$

[29] Mkrttchian, V., Kharicheva, D., Aleshina, E., Panasenko, S., Vertakova, Y., Gamidullaeva, L. A., Chernyshenko, V. (2020). Avatar-based learning and teaching as a concept of new perspectives in online education in Post-Soviet Union countries: Theory, environment, approaches, tools. International Journal of Virtual and Personal Learning Environments (IJVPLE), 10(2), 66-82. https://doi.org/10.4018/ijvple.2020070105

\section{Author}

Jiyu Zheng is from Dangshan, Anhui Province, Ph.D., lecturer. Research interests: safety management, mine safety, etc. Engaged in the teaching of safety science and engineering.

Article submitted 2020-07-31. Resubmitted 2020-08-27. Final acceptance 2020-08-28. Final version published as submitted by the authors. 